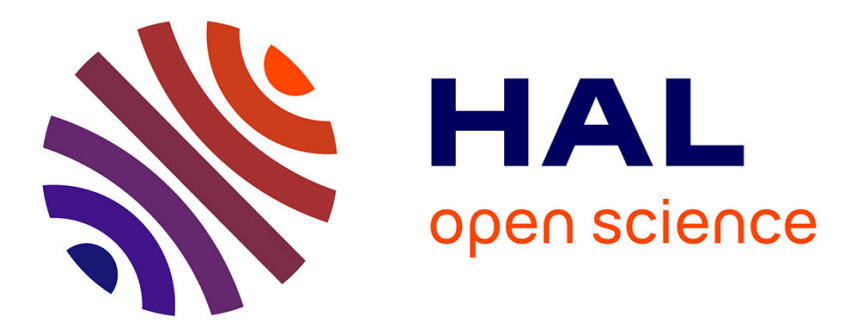

\title{
Mapping upper mantle flow beneath French Polynesia from broadband ocean bottom seismic observations
}

Guilhem Barruol, D. Suetsugu, H. Shiobara, H. Sugioka, S. Tanaka, Goetz Bokelmann, Fabrice R. R. Fontaine, D. Reymond

\section{- To cite this version:}

Guilhem Barruol, D. Suetsugu, H. Shiobara, H. Sugioka, S. Tanaka, et al.. Mapping upper mantle flow beneath French Polynesia from broadband ocean bottom seismic observations. Geophysical Research Letters, 2009, 36 (14), pp.L14301. 10.1029/2009GL038139 . hal-00420907

\section{HAL Id: hal-00420907 https://hal.science/hal-00420907}

Submitted on 5 Oct 2016

HAL is a multi-disciplinary open access archive for the deposit and dissemination of scientific research documents, whether they are published or not. The documents may come from teaching and research institutions in France or abroad, or from public or private research centers.
L'archive ouverte pluridisciplinaire HAL, est destinée au dépôt et à la diffusion de documents scientifiques de niveau recherche, publiés ou non, émanant des établissements d'enseignement et de recherche français ou étrangers, des laboratoires publics ou privés. 


\title{
Mapping upper mantle flow beneath French Polynesia from broadband ocean bottom seismic observations
}

\author{
G. Barruol, ${ }^{1}$ D. Suetsugu, ${ }^{2}$ H. Shiobara ${ }^{3}$ H. Sugioka, ${ }^{2}$ S. Tanaka, ${ }^{2}$ G. H. R. Bokelmann, ${ }^{1}$ \\ F. R. Fontaine, ${ }^{4}$ and D. Reymond ${ }^{5}$ \\ Received 18 March 2009; revised 17 June 2009; accepted 22 June 2009; published 21 July 2009.
}

[1] Upper mantle structures and flow related to the South Pacific Superswell and to the associated short-lived hotspots are investigated using seismic stations deployed in French Polynesia. Beside island stations, broadband ocean bottom seismometers (BBOBS) have been deployed between the various Polynesian archipelagos to investigate the oceanic upper mantle "unperturbed" by thickened crust or hotspot activity. We investigate seismic anisotropy measured at BBOBS stations and found it rather similar to that from island stations. This confirms the ability of OBS to be used for anisotropy purposes and suggests some homogeneity in the upper mantle pervasive deformation. The two OBS installed on the head of the Society hotspot provide different anisotropy signatures than most of the other French Polynesian stations: one is "isotropic" to SKS waves and the other provides a fast split direction normal to the average value observed in this area, suggesting a more complex mantle flow induced by the plume upwelling. Citation: Barruol, G., D. Suetsugu, H. Shiobara, H. Sugioka, S. Tanaka, G. H. R. Bokelmann, F. R. Fontaine, and D. Reymond (2009), Mapping upper mantle flow beneath French Polynesia from broadband ocean bottom seismic observations, Geophys. Res. Lett., 36, L14301, doi:10.1029/ 2009GL038139.

\section{Introduction}

[2] Seismic anisotropy is a powerful tool to study mantle dynamics and particularly to constrain deformation and flow within the Earth since it results from preferred orientations of elastic anisotropy of rock-forming minerals - particularly olivine -, in response to tectonic strain [e.g., Mainprice et al., 2000]. The sub-oceanic mantle is an interesting target, due to the well-organized geodynamic processes that may control it. At large scale lengths of thousand of kilometers, seismic surface waves provided important structural constraints [e.g., Montagner, 2002]. At shorter scale lengths, seismic anisotropy could enlighten small-scale convection and plume-lithosphere interaction through shear wave splitting that provides key parameters of upper mantle anisotropy: the delay time $(\delta t)$ between the two split waves, and the azimuth of the fast split wave polarization $(\varphi)$ that are related to the orientation and

\footnotetext{
${ }^{1}$ Géosciences Montpellier, Université Montpellier II, CNRS, Montpellier, France.

${ }^{2}$ Institute for Research on Earth Evolution, Japan Agency for Marine-Earth Science and Technology, Yokosuka, Japan.

${ }^{3}$ Earthquake Research Institute, University of Tokyo, Tokyo, Japan.

${ }^{4}$ Laboratoire GéoSciences Réunion, Université de la Réunion, CNRS, Saint Denis, Reunion, France.

${ }^{5}$ LDG, Commissariat à l'Energie Atomique, Papeete, French Polynesia.
}

Copyright 2009 by the American Geophysical Union. 0094-8276/09/2009GL038139\$05.00 strength of the pervasive fabric (foliation and lineation) in the anisotropic structure. Despite a poor vertical resolution, SKS waves have Fresnel zones radius of about 40 to $60 \mathrm{~km}$ at depth of 100 and $200 \mathrm{~km}$, respectively, that make them well suited to investigate upper mantle beneath a receiver with a lateral resolution of few tenths of $\mathrm{km}$. Constraining the vertical source of anisotropy using Fresnel zone overlapping [e.g., Margheriti et al., 2003], is unfortunately not possible in this work due to the large station spacing.

[3] SKS splitting techniques have not yet been applied frequently to ocean basins, due to the sparse instrumental coverage, and to a lesser degree the rather high swell-induced microseismic noise level [e.g., Barruol et al., 2006]. If Fontaine et al. [2007] have shown that the swell has a limited influence on the SKS splitting measurement, the seismic stations in oceanic domains are generally situated on islands that represent the surface signature of active or frozen volcanic structures. Seismic waves recorded at island stations likely cross a "perturbed" mantle which can be associated to a locally hotspot-induced thickened crust that may cause waveform complexities and raise the question to which degree island stations give results that are typical for the 'unperturbed' mantle. Deploying ocean bottom seismometers on the ocean floor far from the hotspot tracks represents therefore a challenging way to record seismic waves that have crossed an unperturbed oceanic upper mantle and a normal oceanic crust.

[4] To investigate upper mantle structure and dynamics of the South Pacific Superswell, passive broadband seismic experiments were conducted in French Polynesia: ten seismic stations were deployed on ocean islands in the frame of the Polynesian Lithosphere and Upper Mantle Experiment (PLUME) between 2001 and 2005 [Barruol et al., 2002], and ten broad band ocean bottom seismometers (BBOBS) were deployed in two experiments covering the periods 2003-2004 (8 instruments) and 2004-2005 (2 instruments) [Suetsugu et al., 2005] (Table 1 and Figure 1). This paper focus on upper mantle seismic anisotropy recorded by the BBOBS on the 'unperturbed' ocean floor in French Polynesia.

\section{Data, Method and Results}

[5] For observing distinct, high signal-to-noise ratio SKS and SKKS phases, we extract and analyze events with magnitude $\left(\mathrm{M}_{\mathrm{w}}\right)$ larger than 6.0 occurring at epicentral distance in the range $85^{\circ}$ to $120^{\circ}$. We obtained 35 events suitable for SKS splitting measurement (Table S1 of the auxiliary material). ${ }^{6}$ Each selected SKS phase has been

\footnotetext{
${ }^{6}$ Auxiliary materials are available in the HTML. doi:10.1029/ 2009GL038139.
} 
Table 1. Station Location and Mean Splitting Parameters Together With Their Error Bars and the Number of Events Used

\begin{tabular}{|c|c|c|c|c|c|c|c|c|}
\hline Station & Latitude $\left({ }^{\circ}\right)$ & Longitude $\left({ }^{\circ}\right)$ & $\Phi\left(^{\circ}\right)$ & $\sigma_{\Phi}\left(^{\circ}\right)$ & $\delta \mathrm{t}(\mathrm{s})$ & $\sigma_{\delta \mathrm{t}}(\mathrm{s})$ & Split Events & Unsplit Events \\
\hline $\mathrm{S} 1$ & -18.4099 & -147.1570 & 21 & 17 & 0.96 & 0.60 & 1 & 8 \\
\hline $\mathrm{S} 2$ & -19.1905 & -145.5131 & - & - & - & - & 0 & 13 \\
\hline FP2 & -13.1429 & -139.0352 & -76 & 6. & 1.37 & 0.35 & 3 & 2 \\
\hline FP3 & -17.4845 & -132.4395 & -67 & 10. & 1.10 & 0.34 & 3 & 6 \\
\hline FP4 & -22.8953 & -142.1277 & -69 & 8. & 1.52 & 0.33 & 3 & 10 \\
\hline FP5 & -26.8952 & -137.3037 & -75 & 9. & 0.93 & 0.26 & 7 & 7 \\
\hline FP6 & -30.6936 & -141.1339 & -60 & 10. & 1.22 & 0.32 & 7 & 8 \\
\hline FP7 & -29.1289 & -147.1915 & -62 & 35 & 0.65 & 0.63 & 1 & 9 \\
\hline FP8 & -26.8334 & -152.2185 & -55 & 9. & 0.93 & 0.33 & 3 & 1 \\
\hline
\end{tabular}

band-pass filtered, typically between 0.02 and $0.2 \mathrm{~Hz}$, to remove high frequency and long period noise. The two splitting parameters, i.e., the azimuth of the fast axis $\varphi$ and the delay time $\delta$ t between the fast and slow components of the two split shear waves were measured using the SplitLab software [Wüstefeld et al., 2008] and the minimum eigenvalue method [Silver and Chan, 1991] that does not assume a radial polarization for the SKS wave, which is useful when the actual orientation of the seismometers on the ocean floor is not accurately known.

[6] This approach allowed measuring 5 to 15 well defined SKS waves at each station. Non-null measurements (Table S2) were obtained at most stations and show a clear presence of energy on the transverse component that is removed after anisotropy correction. A quality factor (good, fair or poor) characterizes the initial signal to noise ratio, the correlation between the fast and slow shear waves, the linear pattern of the particle motion in the horizontal plane after correction, and the size of the $95 \%$ confidence region. Examples of measurements are presented in Figures 2 and S1.

[7] A large number of events provided "null" measurements (Table S3), i.e., were devoid of energy on the transverse component. At the "FP..." stations most of the unsplit SKS waves arrived from the NW and are compatible with the non-null measurements, suggesting that incoming SKS waves were polarized parallel to the fast direction in the anisotropic medium [e.g., Wüstefeld and Bokelmann, 2007]. Stations S1 and S2 deployed in the vicinity of the Society hotspot provided mostly null splitting measurements with a much larger backazimuthal coverage, suggesting a vertical isotropy, similar to station PPT in Tahiti [Barruol and Hoffmann, 1999; Fontaine et al., 2007]. Interestingly, the event 2005-036 provided a null splitting measurement at $\mathrm{S} 2$ but a good non-null at $\mathrm{S} 1\left(\varphi=\mathrm{N} 21^{\circ} \mathrm{E}\right.$, $\delta \mathrm{t}=0.96 \mathrm{~s}$, Figure S1), suggesting short-scale mantle structure variations beneath this area.

\section{Discussion}

[8] Individual measurements of good and fair quality (Table S2) are mapped in Figure 1, together with the measurements previously performed in the framework of the PLUME experiment [Fontaine et al., 2007]. The most striking feature is the overall similarity in the trend of $\varphi$ obtained at the BBOBS and at neighboring ocean island

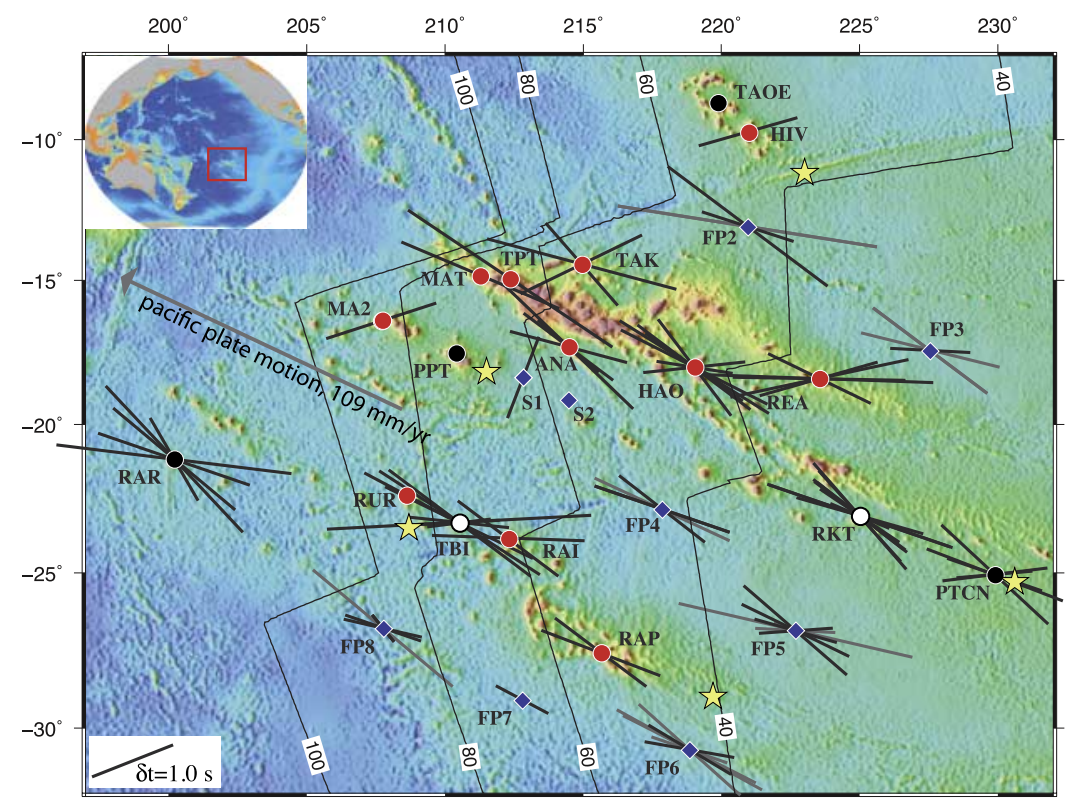

Figure 1. Bathymetric map of French Polynesia, showing the BBOBS (blue diamonds), the PLUME (red circles), the IRIS/GEOSCOPE (black circles), and the LDG/CEA stations (white circles). Stars indicate locations of hotspots. Black bars represent good and gray bars fair quality measurements: The azimuth of each bar represents the fast split direction and its length the delay time between the two split arrivals. 
FP5, event 2003/06/23, Baz N333.4 ${ }^{\circ}$, dist. 88.1 ${ }^{\circ}$
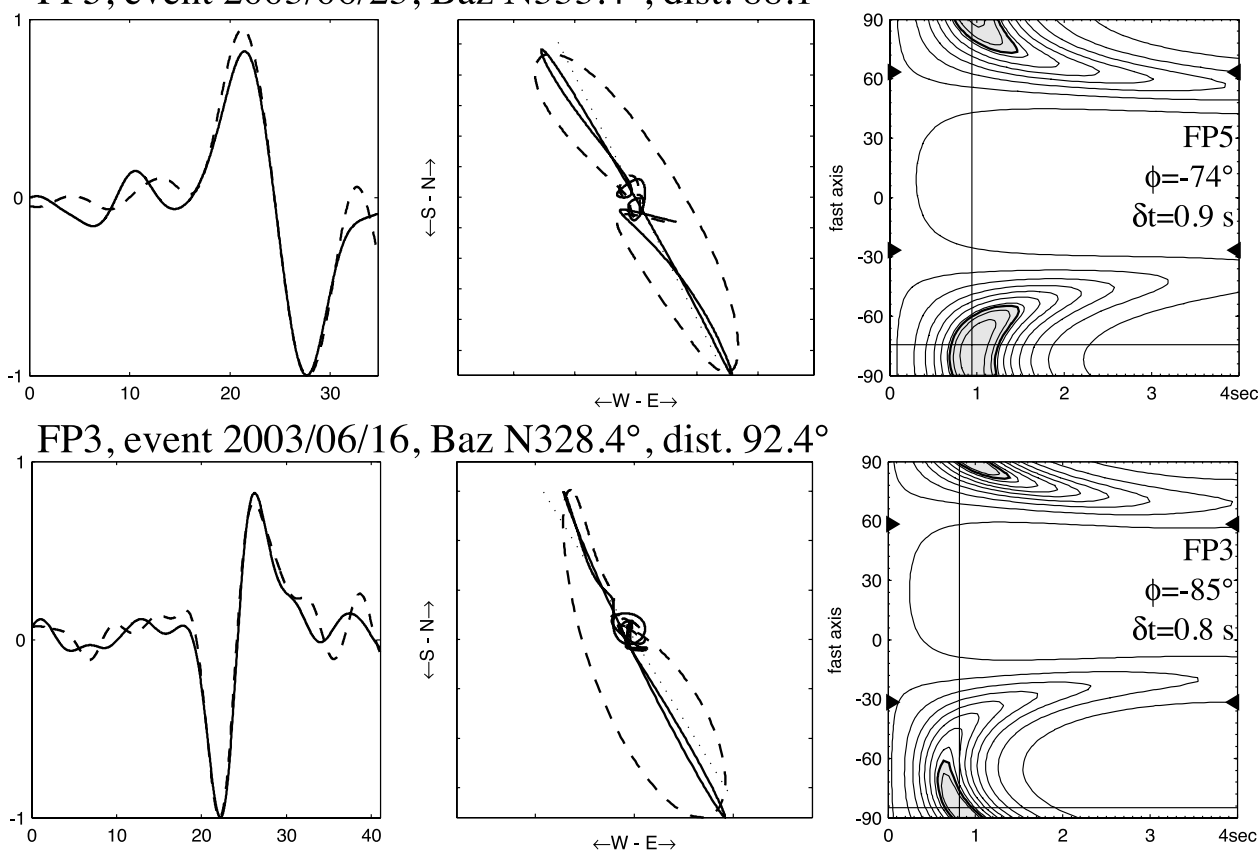

Figure 2. Examples of splitting measurements obtained at stations FP3 (event 2003/06/16 22:08) and FP5 (2003/06/23 12:12) showing (left) the superimposed fast and (time-shifted) slow components of the SKS wave, (middle) the horizontal particle motion before (dashed line) and after (continuous line) anisotropy correction and (right) the map of the eigenvalues showing the best $(\varphi, \delta \mathrm{t})$ anisotropy parameters and the $95 \%$ confidence region.

stations: With the exception of station $\mathrm{S} 1$ at which only a single non-null measurement has been obtained ( $\varphi$ trending $\mathrm{N} 21^{\circ} \mathrm{E}$ ), the trend of $\varphi$ measured at the 7 other BBOBS ranges between $\mathrm{N} 76^{\circ} \mathrm{W}$ and $\mathrm{N} 55^{\circ} \mathrm{W}$, with a mean value of $\mathrm{N} 66^{\circ} \mathrm{W}$, very close to the trend of the Pacific absolute plate motion (N67 $7^{\circ} \mathrm{W}$ [Gripp and Gordon, 2002]), suggesting an important effect from the drag-induced asthenospheric deformation. The observed mean $\delta \mathrm{t}$ range between 0.65 and $1.52 \mathrm{~s}$ (Table 1), and may be acquired along 70 and $150 \mathrm{~km}$ long path for 4 to $5 \% \mathrm{~S}$-wave anisotropy that are considered as typical upper mantle anisotropy magnitudes as observed from mantle rocks [e.g., Mainprice et al., 2000]. Assuming the oceanic lithospheric thickness $e$ is related to plate age $t$ through a relation such as $e=9.1 \cdot t^{0.5}$, [e.g., Fowler, 1990; Parsons and McKenzie, 1978] with $e$ in $\mathrm{km}, t$ in Ma, the lithosphere beneath French Polynesia should be $50 \mathrm{~km}$ thick in the east ( $30 \mathrm{Ma}$ old) to $86 \mathrm{~km}$ thick in the west $(90 \mathrm{Ma}$ old). Using $5 \%$ of anisotropy magnitude, such lithosphere thicknesses should generate $\delta$ t ranging between 0.5 to $0.9 \mathrm{~s}$, and can hardly explain the whole anisotropy signal. The absence of correlation between the plate age and $\delta \mathrm{t}$ but also the fact that smaller anisotropies (2 to $3 \%$ ) are generally observed for waves propagating normal to the foliation plane (expected for the oceanic lithosphere) suggest that the underlying asthenosphere contribute to the observed $\delta$ t.

[9] The second characteristic feature of the BBOBS splitting measurements is the apparent scatter in the $\varphi$ and $\delta \mathrm{t}$ values, rather similar to what is observed at the island permanent and temporary stations in French Polynesia. Despite the rather large error bars of the individual measurements (Table S2) and although the present OBS dataset is too small to allow testing the actual origin of this scatter, the backazimuthal dependence of splitting parameters could result from the presence of two anisotropic layers. SKS splitting at the PLUME stations [Fontaine et al., 2007], P-wave polarization analysis at PPT [Fontaine et al., 2009] and surface wave azimuthal anisotropy of the Pacific upper mantle [e.g., Maggi et al., 2006b; Montagner and Tanimoto, $1991]$ all suggest independently a two layered structure with a lower anisotropic layer related to asthenospheric flow controlled by the absolute plate motion and an upper anisotropic layer within the lithosphere related to the paleo-spreading direction.

[10] Among the nine BBOBS that provided good quality data, S1 and S2 are of particular importance since they were installed slightly upstream from the Society hotspot. If one considers Mehetia Island $\left(212.0^{\circ} \mathrm{E},-17.9^{\circ} \mathrm{N}\right)$ as the most recent surface expression of the Society hotspot [e.g., Clouard and Bonneville, 2005], S1 and S2 are respectively at 100 and $300 \mathrm{~km}$ southeast of this island. The upwelling is probably not a vertical and short-scale structure beneath the hotspot surface expression: numerical modeling of hotspots [Ribe and Christensen, 1994; Thoraval et al., 2006] proposed conduits diameters in the upper mantle between 30 and $70 \mathrm{~km}$ and a general bending in the direction of the plate motion induced by the plate drag, inducing possible offsets up to several hundreds of $\mathrm{km}$ between the hotspot root at the base of the upper mantle and its surface expression. Rayleigh wave tomographies of the Pacific ocean including PLUME data [Isse et al., 2006; Maggi et al., 2006a] evidence a vertical low velocity anomaly beneath the Society hotspot, about $400 \mathrm{~km}$ broad, rooted down to the transition zone, that could correspond to the thermal anomaly induced by the mantle upwelling, consistent with the thinned transition zone shown by receiver function analyses [e.g., Suetsugu et al., 2007]. S2 does not show 


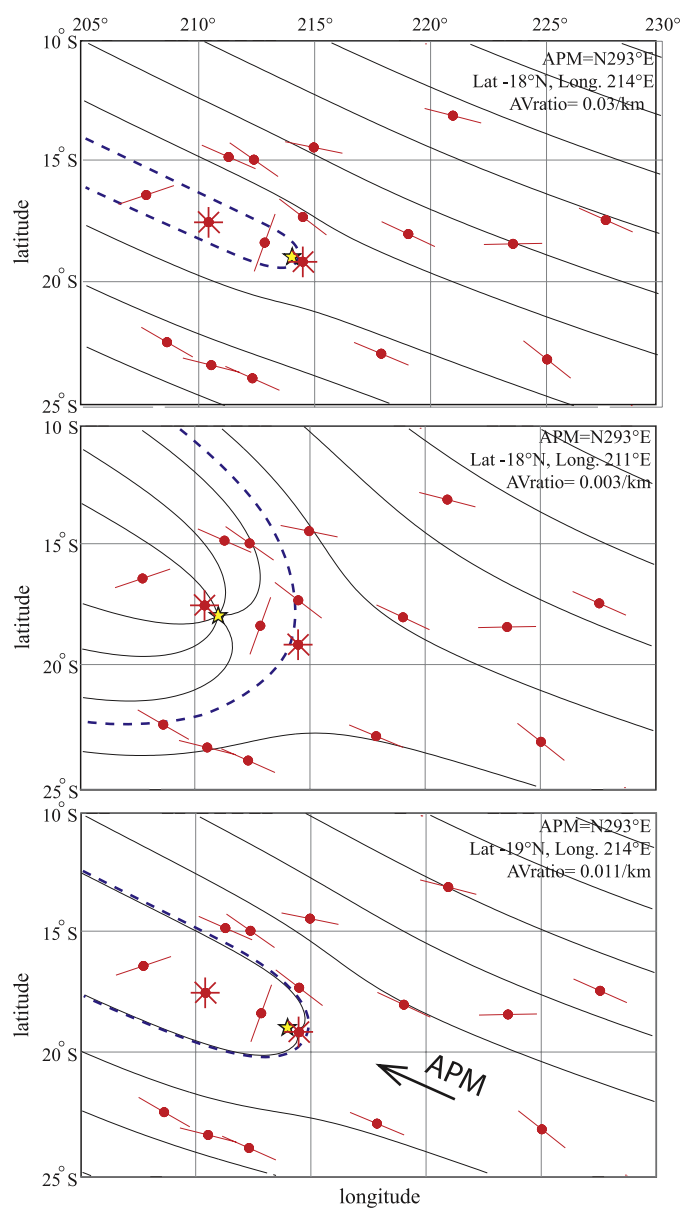

Figure 3. Flow lines from three parabolic asthenospheric flow models for French Polynesia presented with the observed fast split directions (see text). In each model, the $\mathrm{APM}$ is fixed at $\mathrm{N} 293^{\circ} \mathrm{E}$. Dashed line indicate the stagnation line. Isotropy at PPT and S2 are indicated by the red stars. The yellow star indicate the plume best location that may explain the stagnation point close to $\mathrm{S} 2$.

evidence of any split SKS phase and provided only 13 null measurements with a good backazimuthal coverage, 7 of which were of good quality (Table S3). Such an apparent SKS isotropy is similar to what is described at PPT in Tahiti [Barruol and Hoffmann, 1999; Fontaine et al., 2007]. This could result from either a vertical mantle flow, from a complex upper mantle structure induced by the recent magmatism, from the interaction between the plume and the drag-induced flow, or from the presence of two anisotropic layers with perpendicular fast directions and similar intrinsic $\delta \mathrm{t}$. P-wave polarization analyses at PPT [Fontaine et al., 2009] suggest that this two-layer solution is unlikely since two layers of anisotropy are indeed evidenced beneath Tahiti, but they are not perpendicular to each other, and both have different $\delta \mathrm{t}$. S1 provided 8 null measurements, 4 being of good quality and a single non-null measurement of good quality $\left(\varphi=\mathrm{N} 21^{\circ} \mathrm{E}, \delta \mathrm{t}=0.96 \mathrm{~s}\right)$, with $\varphi$ oriented normal to both the mean $\varphi$ trend and to the Pacific APM.

[11] Could the complex pattern of splitting observed at $\mathrm{S} 1$ and $\mathrm{S} 2$ be caused by mantle flow associated with the plume active upwelling? Interaction of an upwelling plume with a fast moving lithosphere may generate a parabolic asthenospheric flow (PAF) beneath the lithosphere [e.g., Ribe and Christensen, 1994; Sleep, 1990], with a symmetry axis parallel to the plate motion and with a flow pattern controlled by the ratio between the plate velocity and the buoyancy flux. Investigating PAF around hotspots, Walker et al. [2005] showed that stations in the neighborhood of the plume head are required to constrain the geometry of the PAF, in particular upstream from the hotspot, where $\varphi$ can differ strongly from APM [Kaminski and Ribe, 2002]. Seismic anisotropy is expected to be null near the "stagnation point" that characterizes the place where the normal asthenospheric flow and the horizontal spreading of the upwelling material beneath the lithosphere cancel each other. The Society stagnation point is expected to be on the southeastern side of the hotspot, i.e., where OBS S1 and S2 were deployed. Available data for French Polynesia allow testing parabolic flow only for the Society hotspot but the limited number of measurements in the area does not allow inverting simultaneously the various parameters controlling the PAF, i.e., the plume location, the azimuth of the plate motion, and the strength of the plume upwelling relative to the plate speed. For this reason, and assuming that a large part of the anisotropy is related to the asthenospheric deformation, we compute forward models of asthenospheric flow using the method proposed by Walker et al. [2005] by fixing the APM to $\mathrm{N} 293^{\circ} \mathrm{E}$ [Gripp and Gordon, 2002], by testing hotspot center around Mehetia island (latitudes: 18 to $21^{\circ}$, longitudes: 210 to $218^{\circ} \mathrm{E}$ ) and by testing ratio of the APM speed to the mass flux rate (AVratio) between $0.03 \mathrm{~km}^{-1}$ and $0.003 \mathrm{~km}^{-1}$.

[12] High values such as $0.03 \mathrm{~km}^{-1}$ (Figure 3, top) characterize a large plate velocity relative to the plume flux and induce a linear parabolic shape that weakly deflect the regional asthenospheric flow. In such case, the stagnation point is close to the hotspot center and has to be very close to S2 to explain the isotropy we observe at this station.

[13] Low values such a $0.003 \mathrm{~km}^{-1}$ (Figure 3, middle) characterize a high plume flux that spreads over large distance from the plume feeding center, implying rotations in the fast split directions at large distances to the hotspot, that are clearly not observed. Such a high value also implies a stagnation point at large distance to the hotspot. To explain the S2 isotropy in term of stagnation point, the hotspot conduit has to be located close to Mehetia island. This suggests a fully vertical feeding of the Society island which is perhaps not realistic in regard of the Pacific plate velocity.

[14] An intermediate model is presented in Figure 3 (bottom), (ratio of $0.011 \mathrm{~km}^{-1}$ ), characterized by a localized effect of the plume upwelling on the mantle flow, restricted to about 200-300 km from the plume head, that may explain the isotropy at PPT and S2 and the slight clockwise rotation of $\varphi$ at ANA. The $\varphi$ direction observed at S1 may represent the tangent of the PAF in this area and its interaction with the overlying lithospheric anisotropy.

\section{Conclusions}

[15] Deployment of broadband OBS in French Polynesia, off the island chains, allowed constraining seismic anisotropy in the upper mantle. Data recorded on the ocean floor 
provided splitting measurements fully comparable to those obtained at the neighboring islands demonstrating 1) the ability of OBS to be used to map upper mantle flow and 2) that the anisotropy signal recorded at island stations is likely not so perturbed by the hotspot activity. The estimated lithosphere thickness (50 to $90 \mathrm{~km}$ ) suggest that it may play an important role (up to $50 \%$ ) in the splitting. However, the average trend of $\varphi$ parallel to the Pacific plate motion indicates a clear signature of the asthenosphere, induced by the displacement of the lithosphere relative to the deeper convective mantle, therefore suggesting the presence of two anisotropic layers. The two stations installed on the top of the Society hotspot provide results different from the other stations: one appears to be "isotropic" to SKS waves and the other provides a single non-null splitting measurement, trending normal to both the average $\varphi$ and to the Pacific APM. Kinematic asthenospheric flow modeling shows that this signature could sign the active mantle upwelling of the Society hotspot.

[16] In order to map shorter scale upper mantle structures above the Society hotspot, 9 BBOBS associated to 9 ocean bottom electro-magnetometers (OBEM) are currently deployed by JAMSTEC for one year, starting in February 2009.

[17] Acknowledgments. The French Polynesia BBOBS array was deployed by a collaborative project of Japan and France. We thank the crew of R/V YOKOSUKA, the Shinkai-6500 team, the JAMSTEC administration. PLUME was funded by the French Ministère de la Recherche. Many thanks to the Centre National de la Recherche Scientifique, to the Université de Polynésie Française, and to the Commissariat à l'Energie Atomique for having made this experiment possible. Thanks to IRIS and GEOSCOPE networks for the high quality data. We thank K. Walker for the parabolic flow analysis and an anonymous reviewer for the comments. SplitLab software and the SKS splitting database are available at http:// www.gm.univ-montp2.fr/splitting/.

\section{References}

Barruol, G., and R. Hoffmann (1999), Seismic anisotropy beneath the Geoscope stations from SKS splitting, J. Geophys. Res., 104, 10,757-10,774, doi:10.1029/1999JB900033.

Barruol, G., et al. (2002), PLUME investigates South Pacific superswell, Eos Trans. $A G U, 83(45), 511$, doi:10.1029/2002EO000354.

Barruol, G., D. Reymond, F. R. Fontaine, O. Hyvernaud, V. Maurer, and K. Maamaatuaiahutapu (2006), Characterizing swells in the southern Pacific from seismic and infrasonic noise analyses, Geophys. J. Int., 164, 516-542, doi:10.1111/j.1365-246X.2006.02871.x.

Clouard, V., and A. Bonneville (2005), Ages of seamounts, islands and plateaus on the Pacific plate, Geol. Soc. Am. Bull., 388, 71-90.

Fontaine, F. R., G. Barruol, A. Tommasi, and G. H. R. Bokelmann (2007), Upper mantle flow beneath French Polynesia from shear-wave splitting, Geophys. J. Int., 170, 1262-1288, doi:10.1111/j.1365-246X.2007. 03475.x.

Fontaine, F. R., G. Barruol, B. L. N. Kenneth, G. H. R. Bokelmann, and D. Reymond (2009), Upper mantle anisotropy beneath Australia and Tahiti from P-wave polarization: Implication for real-time earthquake location, J. Geophys. Res., 114, B03306, doi:10.1029/2008JB005709.

Fowler, C. M. R. (1990), The Solid Earth: An Introduction to Global Geophysics, 472 pp., Cambridge Univ. Press, Cambridge, U. K.

Gripp, A. E., and R. B. Gordon (2002), Young tracks of hotspots and current plate velocities, Geophys. J. Int., 150, 321-361, doi:10.1046/ j.1365-246X.2002.01627.x.

Isse, T., D. Suetsugu, H. Shiobara, H. Sugioka, K. Yoshizawa, T. Kanazawa, and Y. Fukao (2006), Shear wave speed structure beneath the South Pacific superswell using broadband data from the ocean floor and islands, Geophys. Res. Lett., 33, L16303, doi:10.1029/ 2006GL026872.

Kaminski, E., and N. M. Ribe (2002), Timescale for the evolution of seismic anisotropy in mantle flow, Geochem. Geophys. Geosyst., 3(8), 1051, doi:10.1029/2001GC000222.

Maggi, A., E. Debayle, K. Priestley, and G. Barruol (2006a), Multi-mode surface waveform tomography of the Pacific ocean: A closer look at the lithospheric cooling signature, Geophys. J. Int., 166, 1384-1397, doi:10.1111/j.1365-246X.2006.03037.x.

Maggi, A., E. Debayle, K. Priestley, and G. Barruol (2006b), Azimuthal anisotropy of the Pacific region, Earth Planet. Sci. Lett., 250, 53-71, doi:10.1016/j.eps1.2006.07.010.

Mainprice, D., G. Barruol, and W. Ben Ismail (2000), The seismic anisotropy of the Earth's mantle: from single crystal to polycrystal, in Earth's Deep Interior: Mineral Physics and Tomography From the Atomic to the Global Scale, Geophys. Monogr. Ser., vol. 117, edited by S. Karato et al., pp. 237-264, AGU, Washington, D. C.

Margheriti, L., F. P. Lucente, and S. Pondrelli (2003), SKS splitting measurements in the Apenninic-Tyrrhenian domain (Italy) and their relation with lithospheric subduction and mantle convection, J. Geophys. Res., 108(B4), 2218, doi:10.1029/2002JB001793.

Montagner, J.-P. (2002), Upper mantle low anisotropy channels below the Pacific plate, Earth Planet. Sci. Lett., 202, 263-274, doi:10.1016/S0012821X(02)00791-4.

Montagner, J. P., and T. Tanimoto (1991), Global upper mantle tomography of seismic velocities and anisotropies, J. Geophys. Res., 96, 20,337-20,351, doi:10.1029/91JB01890.

Parsons, B., and D. McKenzie (1978), Mantle convection and the thermal structure of the plates, J. Geophys. Res., 83, 4485-4496, doi:10.1029/ JB083iB09p04485.

Ribe, N. M., and U. R. Christensen (1994), Three-dimensional modeling of plume-lithosphere interaction, J. Geophys. Res., 99, 669-682, doi:10.1029/93JB02386.

Silver, P. G., and W. W. Chan (1991), Shear wave splitting and subcontinental mantle deformation, J. Geophys. Res., 96, 16,429-16,454, doi:10.1029/91JB00899.

Sleep, N. H. (1990), Hotspots and mantle plumes: Some phenomology, J. Geophys. Res., 95, 6715-6736, doi:10.1029/JB095iB05p06715.

Suetsugu, D., et al. (2005), Probing South Pacific mantle plumes with ocean bottom seismographs, Eos Trans. AGU, 86(44), doi:10.1029/ 2005EO440001.

Suetsugu, D., H. Shiobara, H. Sugioka, Y. Fukao, and T. Kanazawa (2007), Topography of the mantle discontinuities beneath the South Pacific superswell as inferred from broadband waveforms on seafloor, Phys. Earth Planet. Inter., 160, 310-318, doi:10.1016/j.pepi.2006.11.011.

Thoraval, C., A. Tommasi, and M. P. Doin (2006), Plume-lithosphere interaction beneath a fast moving plate, Geophys. Res. Lett., 33, L01301, doi:10.1029/2005GL024047.

Walker, K. T., G. H. R. Bokelmann, S. L. Klemperer, and A. A. Nyblade (2005), Shear-wave splitting around hotspots: Evidence for upwellingrelated mantle flow?, in Plates, Plumes, and Paradigms, edited by G. R. Foulger et al., pp. 171-192, Geol. Soc. of Am., Boulder, Colo.

Wüstefeld, A., and G. H. R. Bokelmann (2007), Null detection in shear wave splitting measurements, Bull. Seismol. Soc. Am., 97, 1204-1211, doi:10.1785/0120060190.

Wüstefeld, A., G. H. R. Bokelmann, C. Zaroli, and G. Barruol (2008), SplitLab: A shear-wave splitting environment in Matlab, Comput. Geosci., 34, 515-528, doi:10.1016/j.cageo.2007.08.002.

G. Barruol and G. H. R. Bokelmann, Géosciences Montpellier, Université Montpellier II, CNRS, F-34095 Montpellier CEDEX 5, France. (barruol@ gm.univ-montp2.fr)

F. R. Fontaine, Laboratoire GéoSciences Réunion, Université de la Réunion, CNRS, 15, rue René Cassin, F-97715 Saint Denis CEDEX 9, Reunion, France.

D. Reymond, LDG, Commissariat à l'Energie Atomique, BP 640, Papeete 98713,Tahiti, Polynésie Française.

H. Shiobara, Earthquake Research Institute, University of Tokyo, 1-1 Yayoi, Bunkyo-ku, Tokyo 113-0032, Japan.

D. Suetsugu, H. Sugioka, and S. Tanaka, Institute for Research on Earth Evolution, Japan Agency for Marine-Earth Science and Technology, 2-15 Natsushima-cho, Yokosuka, Kanagawa 237-0061, Japan. 